\title{
Useful Activities and Peer Evaluation in Creating PowerPoint Slides to Introduce a Book
}

\author{
Isao Miyaji \\ National Institute of Technology, Toyama College, Japan
}

\begin{abstract}
This paper reports how university students recommended books they are interested in by means of PowerPoint slides in order to equip with computer knowledge and skills. In this course, they were required to create PowerPoint slides to introduce a book by inserting animations and narrations. It applied active learning in combination with evaluation and revision activities to (1) enhance their computer skills; (2) raise awareness towards various types of skills necessary for problem solving and (3) nurture active thinking. It particularly aims not only to acquire PowerPoint skills but also to develop their skills in expression, project planning and suggestion. The useful activities for improving awareness were investigated after the lecture course. The useful activities are counted and created crosstabulation. The activities are added concerning awareness and activities. Clusters analysis is conducted to classify awareness and activities. By using obtained clusters, the first cross-tabulation is reduced. $x^{2}$ test is conducted by using this table as contingency table. The residual analysis is conducted for the table. Self-evaluation and evaluation by others were surveyed at the first and the last week. Significance test is conducted for the response. This paper, thus, informs of the content of the course and proves results of the useful activities, the selfevaluation and the evaluation by others as its effectiveness.
\end{abstract}

\section{Introduction}

There are a number of attempts to propose new ways of teaching and to practice effective classrooms. Currently, the Central Council for Education points out the importance of active learning that students actively discover and solve problems [6]. It therefore encourages Japanese higher education to provide students with high quality education by promoting such active learning so that students are able to experience autonomous learning and acquire lifelong learning skills [8].

In the previous studies, I have identified the possibility of active learning for enhancing problem solving skills and nurturing active thinking in the classroom by applying the activities of self- evaluation, mutual assessment and revision in a task [7].

There are some studies concerning storytelling. Creative activities that produce works that inform and entertain people by describing real and imaginary events, using graphics, narration, and music are called storytelling [3], [18]. In digital storytelling, still pictures such as photographs, figures, and drawn pictures are displayed sequentially to create a storytelling and narrated. Digital stories can be easily reconstructed. Still pictures are easy to handle for the producers of such assignments, and students can reflect upon memories or what they have learned through reviewing still pictures [2]. Kelleher [4] proposed to use storytelling to motivating programming. Tsou [17] explained that storytelling is a practical and powerful teaching tool, especially for language learning. Digital storytelling is in a good position to help teachers use technology in their classrooms effectively [16].

Ballast [1] has reported that the practical class improved the quality of their text narratives through the practice of digital storytelling, compared to the control class that did not practice it. $\mathrm{Ku}$ et al. [5] reported that storytelling task showed effect of similar patterns to the other tests in written language comprehension.

One of my studies reported that university students enhanced their problem solving skills in an experimental course called 'Creating Storytelling' [9]. In this program, they were required to create stories about themselves in order to closely observe and understand who they were. Furthermore, in the process of creating the stories evaluation and revision activities were applied. Awareness improved by these activities was reported as learning effects [10]. It was shown that computer literacy through creating storytelling improved [13].

Another study of mine identified the effectiveness of a task to create PowerPoint slides to introduce commodities in the classroom [11], [12]. It aimed not only to enhance students' computer skills but also to develop their expressive skills, project planning technique and proposal ability. Students created slides presenting products in which they were interested, inserting animation and recording narration. This class combined evaluation and revision activities and implemented active learning and, awareness relating to a variety of skills required 
for problem solving were enhanced in an attempt to cultivate independent thinking skills. It was reported that these skills improved and useful activities in improving awareness were revealed [15].

Following this task, which consisted of seven lessons in total, we provided students with another seven lessons to create slides for book recommendation, which is the main data of this paper. This time, the structure of the course applied active learning so that they must have actively participated in the task in the classroom. They created slides to inform books they are interested in by using animations and narrations. All activities among seven lessons were same as activities in the task to create PowerPoint slides to introduce commodities. The required time and change of awareness were reported as the learning effects [14].

This paper firstly explains the course content, the contents of the slides they made. Secondly after explaining evaluation items in the assessment sheet, we will analyze the useful activities, the selfevaluation and the evaluation by others. Then we discuss the results. Finally, we will demonstrate the difference in the useful activities between these two tasks (introducing commodities and books).

\section{Course contents}

\subsection{Course contents and purpose}

The course in this study is categorized in subjects of Information Technology (see Table 1), which is a compulsory subject for the third year students in A university. Students were required to choose one theme from three and the course was conducted according to the selected theme for 15 times (90 minutes per lesson). The number of the students who enrolled my course was 26 , about one third of the whole third year students. In this course, students were required to create two different slides to introduce commodities and books (see Table 1 for the course procedure). The former seven lessons were for product recommendation and the latter seven for book recommendation. Slide observation and evaluation were conducted twice and revision was undertaken once throughout the tasks.

In this paper, we focus on the latter task: book recommendation. The objectives of this course were (1) to acquire computer knowledge by actually using computers and (2) to make use of such knowledge in practice. It also aimed to introduce books they were moved and found interesting and useful to recommend others to read them. Students created six slides consisting of book information, summary, reasons why they recommend, tips for reading and related books. They had to use animations for easy understanding and recorded narrations in the slides. Through all of these processes, they were able to acquire writing skills and expressive skills by using pictures and diagrams. In this way, the purposes of the program were to raise students' awareness towards various skills necessary for problem solving and to nurture active thinking by applying evaluation activities in the creative task.

\subsection{Course Schedule}

In this task, students had to consider how to recommend a book in an attractive way, including the way of explaining the book and how to insert visual images and photos such as cover pages. The course encouraged students to learn (1) how to express their thoughts and feelings towards the books by writing, images, animations and narrations and (2) how to encourage others to read the books they like. The course does not end by merely creating slides; students observe all the slides, evaluate each other and revise them.

In the first lesson, a 39-page booklet (see Table 2 shown in [15]) to explain the course objective, content, schedule, how to make slides and the way of experiment were distributed to the students. How to use animation and to record narration are already explained at the second and third lesson respectively in the previous task. An image sheet for book recommendation was also provided in the seventh lesson (see Figure 1). Students were required to explain the contents of books for recommendation at the right page of the sheet, draw a figure at the left page and bring it for the next lesson. In the eighth lesson, we made students to create slides by consulting a sample of PowerPoint slides. In the ninth lesson, students added animations in their slides. In the tenth lesson, students recorded narrations and completed the book recommendation slides. They submitted the files and we combined them into one file. In the eleventh lesson, students watched all the slides in the classroom for evaluation. The evaluation results were written on the assessment sheets and they were collected at the end of the class. After that, they revised their slides according to the peer evaluation and the feedback of a teacher. In the following twelfth lesson they again watched the revised slides and assessed them again. The evaluation sheets were collected at the end of the class.

Students wrote final reports. They submitted onethird each on the previous days of the eleventh, twelfth and thirteenth lessons. They were returned with the teacher's comments within the lessons. They then completed the reports at the thirteenth, the fourteenth, and the fifteenth lesson. They also filled in and submitted all the evaluation sheets.

A Word format document for book recommendation, a sample of PowerPoint slides, a document for final report and an evaluation sheet in an Excel format can be downloaded through the elearning system. The evaluation sheet was made 
according to the one used for classroom evaluation for teachers, including self-evaluation (three times), other's evaluation (twice), evaluation by others (twice), pre- and post- evaluations of awareness relating to developed skills and usability of software. Students were required to download these documents, and fill them in as records.
An evaluation sheet necessary for classroom assessment was made in an Excel format. It is a questionnaire including self-evaluation (three times), others' evaluation (twice), evaluation by others (twice), evaluation of awareness relating to developed skills between pre- and post-lessons and usability of computers.

Table 1. Course schedule

\begin{tabular}{|c|c|c|}
\hline Time & Class plan & Plan related to assignment \\
\hline 1 & Explaining Experiment method & $\begin{array}{l}\text { Problem description, information retrieval, considering the } \\
\text { description to introduce, inputing evaluation sheet } 1\end{array}$ \\
\hline 8 & Creating slides to introduce books & $\begin{array}{l}\text { Submission of the entry form, creating slide, completion of } \\
\text { the report }\end{array}$ \\
\hline 9 & II & Creating slide, putting the animation \\
\hline 10 & II & Creating slide, recording narration, writing report 1 \\
\hline 11 & $\begin{array}{l}\text { Review of other slides, evaluation by others } \\
\text { and correction of slides to introduce books }\end{array}$ & $\begin{array}{l}\text { Mutual evaluation, inputting evaluation sheet } 2 \text {, modifying } \\
\text { slide, writing report } 2\end{array}$ \\
\hline 12 & $\begin{array}{l}\text { Review of other slides, evaluation by others } \\
\text { for slides and writing a report }\end{array}$ & $\begin{array}{l}\text { Mutual evaluation, inputting evaluation sheet } 3 \text {, writing } \\
\text { report } 3\end{array}$ \\
\hline 13 & $\begin{array}{l}\text { Completion of the report and the evaluation } \\
\text { sheet to introduce books }\end{array}$ & Revising and submiting report and an evaluation sheet \\
\hline 14 & 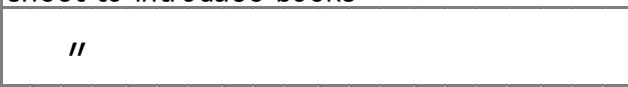 & $\begin{array}{l}\text { Repeating a correction and submission until a report and } \\
\text { an evaluation sheet are completed }\end{array}$ \\
\hline 15 & "I & Completing report to introduce books \\
\hline
\end{tabular}

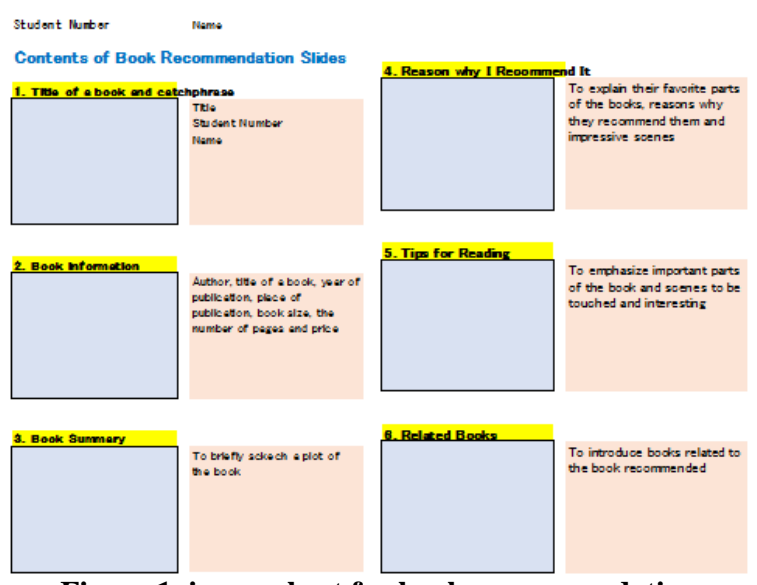

Figure 1. image sheet for book recommendation

\section{The contents of book recommendation slides}

The purpose of this task is to consider how to encourage people to read what students recommend and to make attractive PowerPoint slides. Therefore students are required to simulate what to do when they are asked to manage a project in the future, to introduce books and insert visual pictures of cover pages in the slides.

Books must be the ones that students found interesting and useful. The number of slides must be six and the presentation must be completed within two minutes. The letter size should be more than 28 although 24 point is acceptable if necessary.

The structure of six slides is as follows;

(1) Title of a book and catchphrase
A catchphrase should be 'a -like (or adjective) book in $\bigcirc \circ$ ' or 'the book of $\bigcirc \circ$ is ...'. A picture of the cover page should be introduced.

(2) Book information

Author, title of a book, year of publication, place of publication, book size, the number of pages and price must be specified.

(3) Book summary

Students must briefly summarize the book in order for others to understand the content of it. By inserting pictures, they must try to visualize the content.

(4) Reason why I recommend it

Students explain their favorite parts of the books, reasons why they recommend them and impressive scenes they found after reading.

(5) Tips for Reading

Students emphasize important parts of the book and scenes to be touched and interesting. They also highlight what they recommend in the book.

(6) Related books

By introducing related books, students will make others to be interested in the book recommended. Book information including the name of an author, title, year of publication, the number of pages and publisher must be specified. It is also possible to introduce several books written by the same author or some books whose stories are similar to the one recommended.

\section{Analysis and results}

In order to understand the effectiveness of learning in creating slides for book recommendation 
explained in the previous section, we conducted several studies. Firstly, by comparing their awareness towards the acquired skills before and after the task we attempted to see the achievement level of the course objective [14]. At the same time, we explored useful activities for raising awareness of the acquired skills after practicing the task because they could be the reasons for students' raising awareness. We count activities useful for raising awareness and create cross-tabulation. We apply cluster analysis, $\chi^{2}$ test, and residual analysis to the cross-tabulation to know useful activities.

\subsection{Categorization of awareness by cluster analysis: Using the number of useful activities for awareness raising}

We set up a row showing awareness relating to 30 kinds of skills and a column signifying 33 activities. The skills are shown in left of Figure 2 and the activities are shown in left of Figure 3. We counted activities useful for raising awareness in both tasks and created a 30 rows $\times 33$ columns cross-tabulation.
Based on this table, we applied Cluster Analysis by following Ward's Method with awareness as cases and activities as variables. By cutting the dendrogram by the dissimilarity 7, awareness can be categorized into three (Categories I-III) as shown in Figure 2. Here the horizontal axis signifies dissimilarity and the vertical axis shows awareness.

The first Category I consists of 21 types of awareness including: (24) self-satisfaction; (25) selfachievement; (26) problem solving skills; (20) skills to ameliorate and improve ideas; (14) skills to explain something in an easy way; (15) presentation skills; (13) skills to express your thoughts without writing; (8) autonomous learning skills; (9) information gathering techniques; (10) data management skills; (11) skills to analyze information; (21) skills to explore something deeply; (5) task setting; (6) task planning; (22) performance; (28) ability to think and produce ideas; (29) creative skills; (27) ability to systematize knowledge; (7) deep understanding of knowledge; (30) interests in this field; (12) writing skills to explain your ideas.

(24) Sense of accomplishment, sense of satisfaction (25) Sense of fulfilment, sense of achievement (26) Ability to solve problems (20) Ability to correct and improve on one's own thoughts (14) Ability to talk to and explain to others comprehensively (15) Ability to make presentations (13) Ability to express thoughts through media other than writing (8) Ability to study by oneself, ability to learn (9) Ability to gather information, ability to conduct research (10) Ability to sort through related information or data (11) Ability to analyse information (21) Ability to pursue matters deeply, ability to explore matters (5) Ability to set challenges, ability to discover problems

(6) Ability to plan, to do things in a planned manner (22) Ability to execute, ability to practice, ability to put into action (28) Ability to think, consider and come up with ideas by oneself

(27) Ability to cons (29) Creativity/ability to creat

(7) Cultivation of understanding of knowledge learned (30) Interest in and curiosity about this field (12) Ability to express thoughts in writing (17) Communication ability

(23) Ability to cooperate and to learn concertedly (16) Ability to listen to others and to ask questions to others

(19) Ability to appropriately evaluate other people's thoughts (18) Ability to appropriately self-evaluate one's thoughts

(2) Understanding of computers

(4) Computer usage methods and broadening of situations

(3) Computer operation skills

(1) Interest in and curiosity about computers

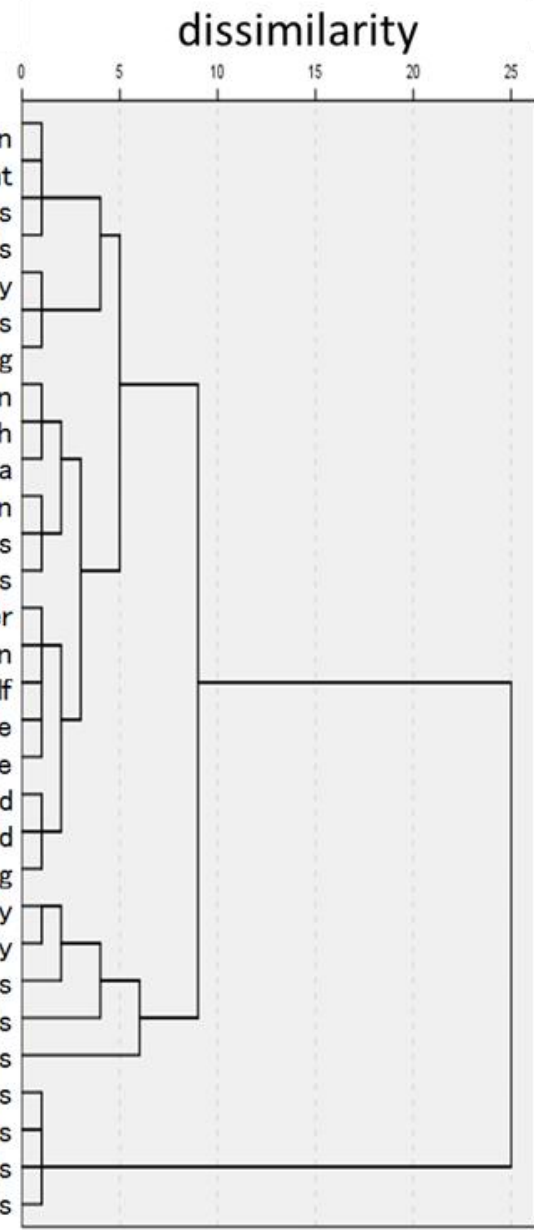

Figure 2. Dendrogram to show awareness clusters acquired by cluster analysis 
The average frequency of useful activities towards these types of awareness was 109.8 , which was a bit smaller than the total average but in the moderate level of frequency. Items (5), (30) and (7) were relatively higher than others. This means that the Category I can be summarized as 'awareness concerning task setting, deep understanding and interest'.

Category II includes five types of awareness: (17) communicative competence; (23) collaborative learning; (16) listening skills to other's talk; (19) evaluation skills towards other's ideas and (18) selfevaluation skills towards own ideas. The average frequency of useful activities for these types of awareness was 109.2, which is a little bit smaller than the total average value. The items (16), (18) and (19) were relatively high so that Category II is 'awareness relating to listening and evaluation'.

The third Category III includes four types of awareness: (1) interests towards computers; (2) understanding of computer; (3) computer skills and (4) how to use computers in broader contexts. The average frequency of useful activities for these types of awareness was 153.3, which was the highest in three categories. All four items were higher than other 26 evaluation items, showing that many activities were useful for raising awareness. Therefore Category III can be 'awareness relating to computer'.

\subsection{Classification of useful activities by cluster analysis of the number of activities for raising awareness}

In order to identify the useful activities for students' raising awareness, we analyzed the $30 \times 33$ cross-tabulation of both tasks used in 6.4. We applied Cluster Analysis by Ward's Method, setting activities as cases and awareness as variables. When cutting the dendrogram by the dissimilarity 7 , the activities were categorized into three clusters (Group 1-3) as in Figure 3.

Group 1 consists of 21 activities including: (20) to reevaluate own slides; (21) to reevaluate own slides again; (19) to evaluate own slides; (22) to watch others' slides; (23) to watch others slides again; (24) to evaluate others' slides; (25) to reevaluate others' slides; (9) to draw figures with paint; (15) to add animation in the slides; (31) to revise the final report; (32) to revise the report according to the teacher's feedback after submission; (29) to revise the slides;

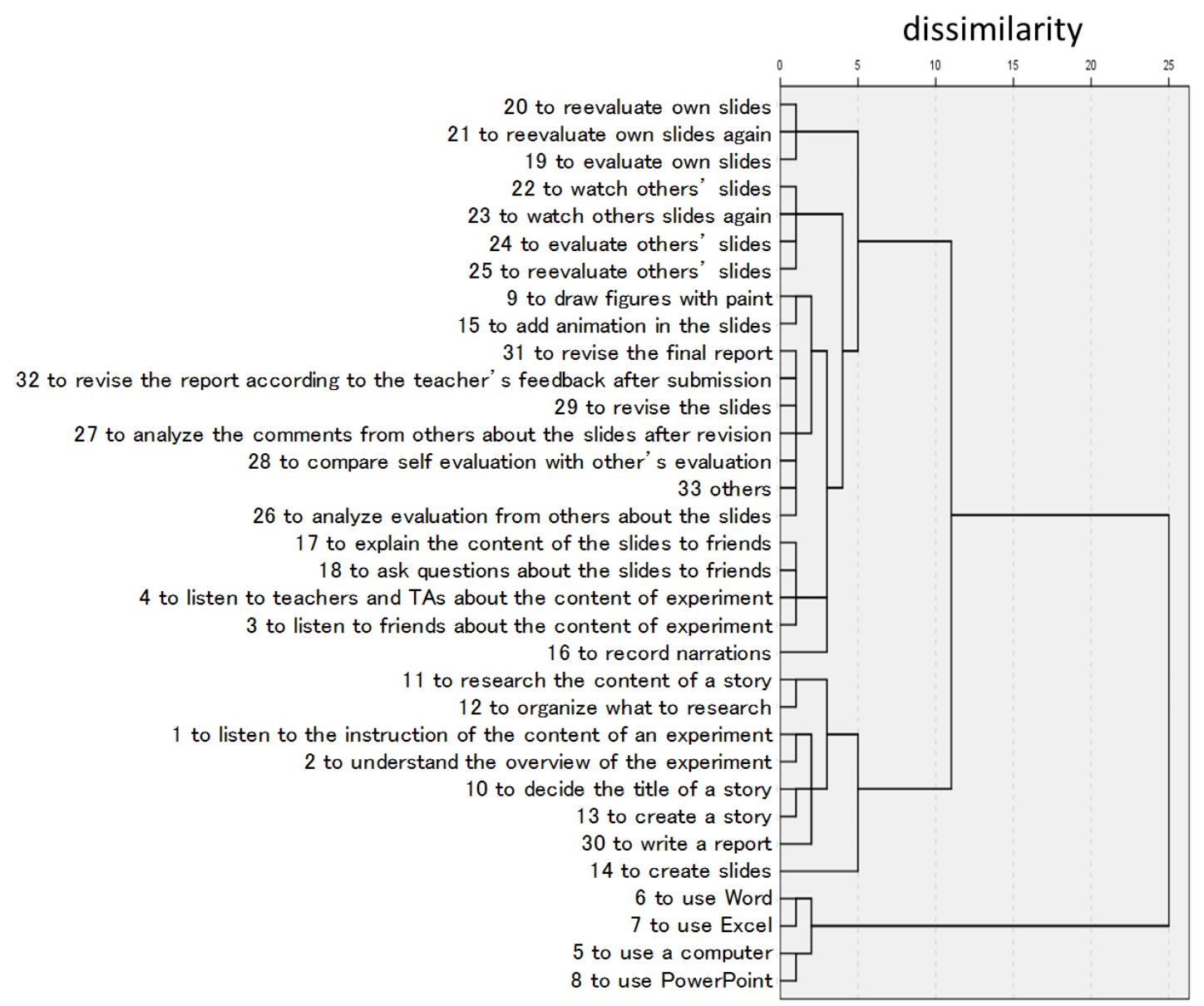

Figure 3. Dendrogram to show activity clusters by cluster analysis 
(27) to analyze the comments from others about the slides after revision; (28) to compare self-evaluation with other's evaluation; (33) others; (26) to analyze evaluation from others about the slides; (17) to explain the content of the slides to friends; (18) to ask questions about the slides to friends; (4) to listen to teachers and TAs about the content of experiment; (3) to listen to friends about the content of experiment and (16) to record narrations. Particularly, the frequency of the items (3) and (16) is high so that this group is classified as 'Activities concerning asking a question or narrations'.

Group 2 consists of 8 activities including (11) to research the content of a story; (12) to organize what to research; (1) to listen to the instruction of the content of an experiment; (2) to understand the overview of the experiment; (10) to decide the title of a story; (13) to create a story; (30) to write a report and (14) to create slides. The frequency of the items (1), (2), (11), (12) and (14) is high so that this group is categorized as 'Activities relating to slide creation'.

Group 3 consists of 4 activities including (6) to use Word; (7) to use Excel; (5) to use a computer and (8) to use PowerPoint. Frequency of all items is high so that the group is called 'Activities relating to software use'.

\subsection{Analytical results about useful activities for students' raising awareness}

A cross-tabulation concerning awareness and activities is 30 rows $\times 33$ columns. By using clusters from both tasks, we aggregated the frequency in the both tasks. The result is shown at the upper left of Table 2. We did $\chi^{2}$ test by using this table as $3 \times 3$ contingency table. The result shows that the deviation of frequency was significant $\left(x^{2}(4)=\right.$ $12618, \mathrm{p}<.001)$. The result of residual analysis is shown at the lower left of Table 2. We put * for the cells whose deviations are positive in the significant cells (see Table 2 at the lower right corner).

By this result, it is identified that Group 1 'Activities concerning asking a question or narrations' is useful for students' raising 'Awareness relating to listening and evaluation', which is Category II.

It is also seen that Group 2, 'Activities relating to slide creation' is useful for raising 'Awareness concerning task setting, deep understanding and interest', which equates to Category I.

Finally, it is found that Group 3, 'Activities relating to software use' is useful for raising 'Awareness relating to computer', which is Category III.

The number of activities enumerated in the classes for introducing commodities and books was 1708 and 1756 respectively. The number of activities enumerated in both classes was the almost same. The useful activity clusters for raising awareness of the acquired skills after practicing the task also for both classes were the same as the cross-tabulation in the both tasks.

\subsection{Change in self-evaluation by creating slides}

After time when the work was finished and time having watched the revised work, students are required to rate oneself works by oneself with five levels for 18 items, input them into an evaluation sheet and submit it. Critical remarks were made with the following five grades: 1 . Contents are insufficient and required levels are hardly fulfilled, 2. Contents do not fulfil required levels, 3. Contents almost fulfil required levels, 4. Contents satisfactorily fulfil required levels and 5. Contents exceeded required levels. 26 students responded two times of the pre

Table 2. Result of $\chi^{2}$ test and residual analysis concerning cross-tabulation on awareness and activity clusters

\begin{tabular}{|c|c|c|c|c|c|c|c|}
\hline \multirow[b]{2}{*}{ Cluster of Activity } & \multicolumn{4}{|c|}{ Observed frequency } & \multicolumn{3}{|c|}{ Expected frequency } \\
\hline & $\begin{array}{c}1 . \\
\text { Activities } \\
\text { concernin } \\
\text { g asking a } \\
\text { question } \\
\text { or } \\
\text { narrations }\end{array}$ & $\begin{array}{c}2 . \\
\text { Activities } \\
\text { relating to } \\
\text { slide } \\
\text { creation }\end{array}$ & $\begin{array}{c}3 . \\
\text { Activities } \\
\text { relating to } \\
\text { software } \\
\text { use }\end{array}$ & Total & $\begin{array}{c}1 . \\
\text { Activities } \\
\text { concernin } \\
\text { g asking a } \\
\text { question } \\
\text { or } \\
\text { narrations } \\
\end{array}$ & $\begin{array}{l}2 . \\
\text { Activities } \\
\text { relating to } \\
\text { slide } \\
\text { creation }\end{array}$ & $\begin{array}{c}3 . \\
\text { Activities } \\
\text { relating to } \\
\text { software } \\
\text { use }\end{array}$ \\
\hline $\begin{array}{l}\text { I .Awareness concerning task setting, deep } \\
\text { understanding and interest }\end{array}$ & 753 & 1092 & 460 & 2305 & 843.1 & 838.4 & 623.5 \\
\hline II. Awareness relating to listening and evaluation & 417 & 80 & 49 & 546 & 199.7 & 198.6 & 147.7 \\
\hline III. Awareness relating to computer & 97 & 88 & 428 & 613 & 224.2 & 223.0 & 165.8 \\
\hline \multirow[t]{2}{*}{ Total } & 1267 & 1260 & 937 & 3464 & 1267.0 & 1260.0 & 937.0 \\
\hline & \multicolumn{3}{|c|}{ Adjusted residual } & & \multicolumn{3}{|c|}{ Significance probability } \\
\hline $\begin{array}{l}\text { I .Awareness concerning task setting, deep } \\
\text { understanding and interest }\end{array}$ & -6.7 & 19.0 & -13.3 & & & $* * *$ & \\
\hline II. Awareness relating to listening and evaluation & 21.0 & -11.5 & -10.4 & & $* * *$ & & \\
\hline III. Awareness relating to computer & -11.8 & -12.5 & 26.3 & & & & $* * *$ \\
\hline
\end{tabular}


and post self-evaluation. Elongation in the two selfevaluations was tested for paired significance difference. These results are shown in Table 3. The result of paired significance difference test showed that average elongation in self-evaluation are significance for overall $(\mathrm{t}(441)=13.6, \mathrm{p}<0.001)$. It was recognize that self-evaluation improved overall.

The results of paired significance difference tests for average values in self-evaluation for each question item showed that average elongation in selfevaluation were significance for all of 18 items as shown in Table 3. They revealed that self-evaluation improved for all items.

The elongation of the self-evaluation seems to be large because the explanation and the narration can be corrected more appropriately than a slide according to looking at the big statistic if the elongation in 3 kinds of the self-evaluation is compared.

\subsection{Change in evaluation by others through two viewings}

Directly after viewing the works the first and second time, evaluation by others was conducted with five grades for the same 18 items as selfevaluation. Evaluation sheets were filled in and submitted. 26 students responded to both evaluation sheets. Elongation in the two evaluations by others was tested for paired significance difference and these results are shown in Table 4 . The results of

Table 3. Results of significance test for two times of self-evaluation

\begin{tabular}{|c|c|c|c|c|c|c|c|c|c|}
\hline \multirow{2}{*}{$\begin{array}{l}\text { Calasifi- } \\
\text { cation }\end{array}$} & \multirow{2}{*}{ Qustion Items } & \multicolumn{2}{|c|}{ Pre } & \multicolumn{2}{|c|}{ Post } & \multicolumn{2}{|c|}{ Elongation } & \multicolumn{2}{|c|}{ t-test } \\
\hline & & $\mathrm{m}$ & SD & $\mathrm{m}$ & SD & $\mathrm{m}$ & SD & $\mathrm{t}$ & $\mathrm{p}$ \\
\hline \multirow{5}{*}{$\begin{array}{l}\text { Expla- } \\
\text { nation }\end{array}$} & (1) Is the composition of the whole explanation appropriate? & 3.0 & 0.4 & 3.7 & 0.6 & 0.6 & 0.7 & 4.3 & **** \\
\hline & (2) Does the explanation accord with a title? & 3.3 & 0.6 & 3.8 & 0.5 & 0.5 & 0.6 & 4.2 & **** \\
\hline & (3) Are you interested in explanation? & 3.1 & 0.6 & 3.8 & 0.5 & 0.8 & 0.8 & 4.7 & **** \\
\hline & (4) Is there a contrivance of clarity in explanation? & 3.0 & 0.6 & 3.6 & 0.6 & 0.5 & 0.7 & 3.7 & $* *$ \\
\hline & (5) Can you understand the book which you were introduced? & 3.2 & 0.8 & 3.9 & 0.6 & 0.7 & 0.7 & 5.0 & $* * *$ \\
\hline \multirow{8}{*}{ Slides } & (6) Does each slide accord with explanation? & 3.4 & 0.5 & 3.8 & 0.6 & 0.4 & 0.6 & 2.9 & ** \\
\hline & (7) Is a slide devised to understand explanation? & 3.2 & 0.5 & 3.6 & 0.6 & 0.4 & 0.7 & 2.9 & *** \\
\hline & (8) Is the composition of the whole slide appropriate? & 3.3 & 0.7 & 3.6 & 0.6 & 0.4 & 0.6 & 3.2 & $* *$ \\
\hline & (9) Is the background of the slide appropriate? & 3.2 & 0.7 & 3.8 & 0.5 & 0.6 & 0.7 & 4.0 & **** \\
\hline & (10) Are the size and the color of the letter appropriate? & 3.2 & 0.6 & 3.5 & 0.6 & 0.3 & 0.5 & 2.9 & *** \\
\hline & (11) Is the thing using for explanation appropriate? & 3.2 & 0.6 & 3.6 & 0.6 & 0.4 & 0.6 & 3.2 & $* *$ \\
\hline & (12) Is the object performing animation appropriate? & 3.1 & 0.5 & 3.6 & 0.7 & 0.4 & 0.7 & 3.2 & *** \\
\hline & (13) Is the target movement performing animation smooth? & 3.0 & 0.6 & 3.5 & 0.7 & 0.4 & 0.7 & 3.2 & $* *$ \\
\hline \multirow{4}{*}{$\begin{array}{c}\text { Narra- } \\
\text { tion }\end{array}$} & (14) Is it easy to hear the voice? & 2.9 & 0.5 & 3.7 & 0.7 & 0.8 & 0.6 & 6.5 & $* * *$ \\
\hline & (15) Are sound and BGM appropriate? & 2.7 & 0.7 & 3.3 & 0.6 & 0.6 & 0.7 & 4.0 & *** \\
\hline & (16) Is the time distribution appropriate? & 3.1 & 0.7 & 3.7 & 0.7 & 0.6 & 0.7 & 4.3 & **** \\
\hline & (17) Is the narration devised to understand explanation? & 3.0 & 0.6 & 3.5 & 0.6 & 0.4 & 0.8 & 2.7 & $*$ \\
\hline \multirow{2}{*}{\multicolumn{2}{|c|}{$\begin{array}{c}\text { (18) How much is the degree that you feel to read the book } \\
\text { Mean }\end{array}$}} & 3.3 & 0.7 & 4.1 & 0.6 & 0.8 & 0.5 & 7.6 & **** \\
\hline & & 3.1 & 0.6 & 3.6 & 0.6 & 0.5 & 0.8 & 13.6 & *** \\
\hline
\end{tabular}

Table 4. Results of significance test for two times of evaluation by others

\begin{tabular}{|c|c|c|c|c|c|c|c|c|c|}
\hline \multirow{2}{*}{$\begin{array}{c}\text { Calasifi- } \\
\text { cation }\end{array}$} & \multirow{2}{*}{ Qustion Items } & \multicolumn{2}{|c|}{ Pre } & \multicolumn{2}{|c|}{ Post } & \multicolumn{2}{|c|}{ Elongation } & \multicolumn{2}{|c|}{ t-test } \\
\hline & & $\mathrm{m}$ & SD & $\mathrm{m}$ & SD & $\mathrm{m}$ & SD & $\mathrm{t}$ 值 & $\mathrm{p}$ \\
\hline \multirow{5}{*}{$\begin{array}{l}\text { Expla- } \\
\text { nation }\end{array}$} & (1) Is the composition of the whole explanation appropriate? & 3.3 & 0.4 & 3.5 & 0.4 & 0.3 & 0.3 & 4.2 & $* * *$ \\
\hline & (2) Does the explanation accord with a title? & 3.3 & 0.4 & 3.5 & 0.4 & 0.2 & 0.3 & 3.7 & ** \\
\hline & (3) Are you interested in explanation? & 3.2 & 0.3 & 3.4 & 0.4 & 0.3 & 0.3 & 3.6 & ** \\
\hline & (4) Is there a contrivance of clarity in explanation? & 3.1 & 0.4 & 3.3 & 0.4 & 0.2 & 0.3 & 3.8 & $* * *$ \\
\hline & (5) Can you understand the book which you were introduced? & 3.2 & 0.3 & 3.4 & 0.4 & 0.3 & 0.3 & 3.8 & *** \\
\hline \multirow{8}{*}{ Slides } & (6) Does each slide accord with explanation? & 3.3 & 0.4 & 3.5 & 0.4 & 0.2 & 0.3 & 3.9 & $* * *$ \\
\hline & (7) Is a slide devised to understand explanation? & 3.1 & 0.4 & 3.3 & 0.4 & 0.2 & 0.3 & 3.6 & ** \\
\hline & (8) Is the composition of the whole slide appropriate? & 3.1 & 0.3 & 3.4 & 0.4 & 0.2 & 0.2 & 4.5 & $* * *$ \\
\hline & (9) Is the background of the slide appropriate? & 3.1 & 0.3 & 3.2 & 0.4 & 0.1 & 0.2 & 2.4 & $*$ \\
\hline & (10) Are the size and the color of the letter appropriate? & 3.0 & 0.4 & 3.1 & 0.5 & 0.1 & 0.3 & 2.3 & $*$ \\
\hline & (11) Is the thing using for explanation appropriate? & 3.1 & 0.3 & 3.2 & 0.3 & 0.1 & 0.2 & 2.9 & ** \\
\hline & (12) Is the object performing animation appropriate? & 3.0 & 0.4 & 3.2 & 0.4 & 0.2 & 0.3 & 4.0 & $* * *$ \\
\hline & (13) Is the target movement performing animation smooth? & 3.0 & 0.4 & 3.2 & 0.3 & 0.2 & 0.2 & 3.4 & ** \\
\hline \multirow{4}{*}{$\begin{array}{c}\text { Narra- } \\
\text { tion }\end{array}$} & (14) Is it easy to hear the voice? & 3.0 & 0.4 & 3.3 & 0.4 & 0.3 & 0.3 & 6.2 & $* * *$ \\
\hline & (15) Are sound and BGM appropriate? & 2.8 & 0.5 & 3.0 & 0.6 & 0.2 & 0.4 & 2.9 & *** \\
\hline & (16) Is the time distribution appropriate? & 3.0 & 0.3 & 3.2 & 0.4 & 0.2 & 0.2 & 5.4 & *** \\
\hline & (17) Is the narration devised to understand explanation? & 2.9 & 0.3 & 3.2 & 0.4 & 0.2 & 0.2 & 6.4 & $* * *$ \\
\hline \multirow{2}{*}{\multicolumn{2}{|c|}{ (18) How much is the degree that you feel to read the book }} & 3.2 & 0.3 & 3.4 & 0.4 & 0.2 & 0.3 & 3.1 & ** \\
\hline & & 3.1 & 0.4 & 3.3 & 0.4 & 0.2 & 0.3 & 15.9 & $* * *$ \\
\hline
\end{tabular}

paired significance difference for overall average assessment values acknowledged significance ( $\mathrm{t}$
$(441)=15.9, \mathrm{p}<0.001)$. It was revealed that evaluation by others improved overall. 
The results of paired significance difference tests for average values in evaluation by others for each question item showed that average elongation in evaluation by others were significance for all of 18 items as shown in Table 4. They revealed that evaluation by others improve for all items.

The elongation of the self-evaluation seems to be large because the explanation and the narration can be corrected more appropriately than a slide according to looking at the big statistic if the elongation in 3 kinds of the self-evaluation is compared. This fact was the same as one of selfevaluation.

It was recognized that the average rating value of "(18) How much is the degree that you feel to read the book introduced?" improved second time. Students interested in the books introduced by others and felt to read the books.

\subsection{Comments in evaluation by others through two viewings}

Students were asked to write the following comments at the end of evaluation by others: Please fill in your thoughts and advice about the book presentation slides. The number of instances of advice for the two viewings were 568/603 and $518 / 577$ respectively and their ratios were $94 \%$ and $90 \%$. Advice was almost always written with respect to evaluation by others for both viewings. The average number of characters for the first and second viewing was 12.5 and 14.0 respectively and there was not much difference between two viewings.

Comment was briefly as follows: Your work is generally good, but I think that your work becomes better if animations are increased; Because there is a too long place, your work becomes better if you shorten it a little more; Your work become better if explanation are organized up a little more briefly because there were too many letters in the slide. Impression was briefly as follows: I think that moving an animation is good; I think that the background may match a book. The average rating value was 3.1 in the first time and became 3.3 in the second time. In the second time, comments praised became more than the first advice by reflecting this fact as follows: It may be easy to hear the narration; I wanted to read this book. Considering the fact that students evaluated 17 question items to evaluate and wrote the comments in the short space of one minute, it is thought that text length of the comment is written well. In addition, it is thought that this amount of advice is of use as a reference for the students who were evaluated. As a result, it is estimated that there was overall improvement due to evaluation by others as explained in section 4.5.

\subsection{Correlation between reports and awareness}

The range of report submissions was 3 to 7 and the average number of times that reports were submitted was 5.6. The following two categories had a significant correlation between elongation in awareness and the number of times that a report was submitted. The correlation coefficient $r$ between the number of submissions of the reports and elongation in (9) 'Ability to gather information' was $r=0.42 *$. The correlation coefficient between the average number of submissions and elongation in (10) 'presentation skills' was $\mathrm{r}=0.42 *$. Both of these correlations were significant with weak correlation. There was no significant correlation among other elongation of awareness. The correlation coefficient between the number of submissions of the reports and score of the report was $r=-0.56^{* *}$. This is significant but medium level correlation.

The range of character numbers written in the 11 discussion categories of the report was between 970 and 6005 and the average number of characters was 2338.8. There was no significant correlation between character numbers and elongation in all of awareness.

\section{Discussion}

\subsection{About useful activities for students' raising awareness}

The number of activities enumerated in the classes for introducing commodities and books was 1708 and 1756 respectively. The number of activities enumerated in both classes was the almost same. The useful activity clusters for raising awareness related to the acquired skills were the same after practicing the task also for both classes.

About two classes in creating introduction slides, I consider the list which added up the number of the activity enumerated for each awareness in contingency table. $\chi^{2}$ test was conducted by using this $2 \times 30$ table as shown in Table 5. The result shows that the deviation of frequency was no significant $\left(\chi^{2}(29)=-314.6, p>.05\right)$. This means that the number of the activity enumerated for each awareness was not different from each other in two classes.

Similarly, I consider the list which added up the number of the enumerated activity for every activity to be contingency table. $\chi^{2}$ test was conducted by using this $2 \times 33$ table as shown in Table 6 . The result shows that the deviation of frequency was significant $\left(\chi^{2}(32)=174.4, \mathrm{p}<.001\right)$. As the result of residual analysis, the numbers of activities 4,8 and 
Table 5. Results of $\chi^{2}$ test by using frequency distribution of the number of activities enumerated for each awareness

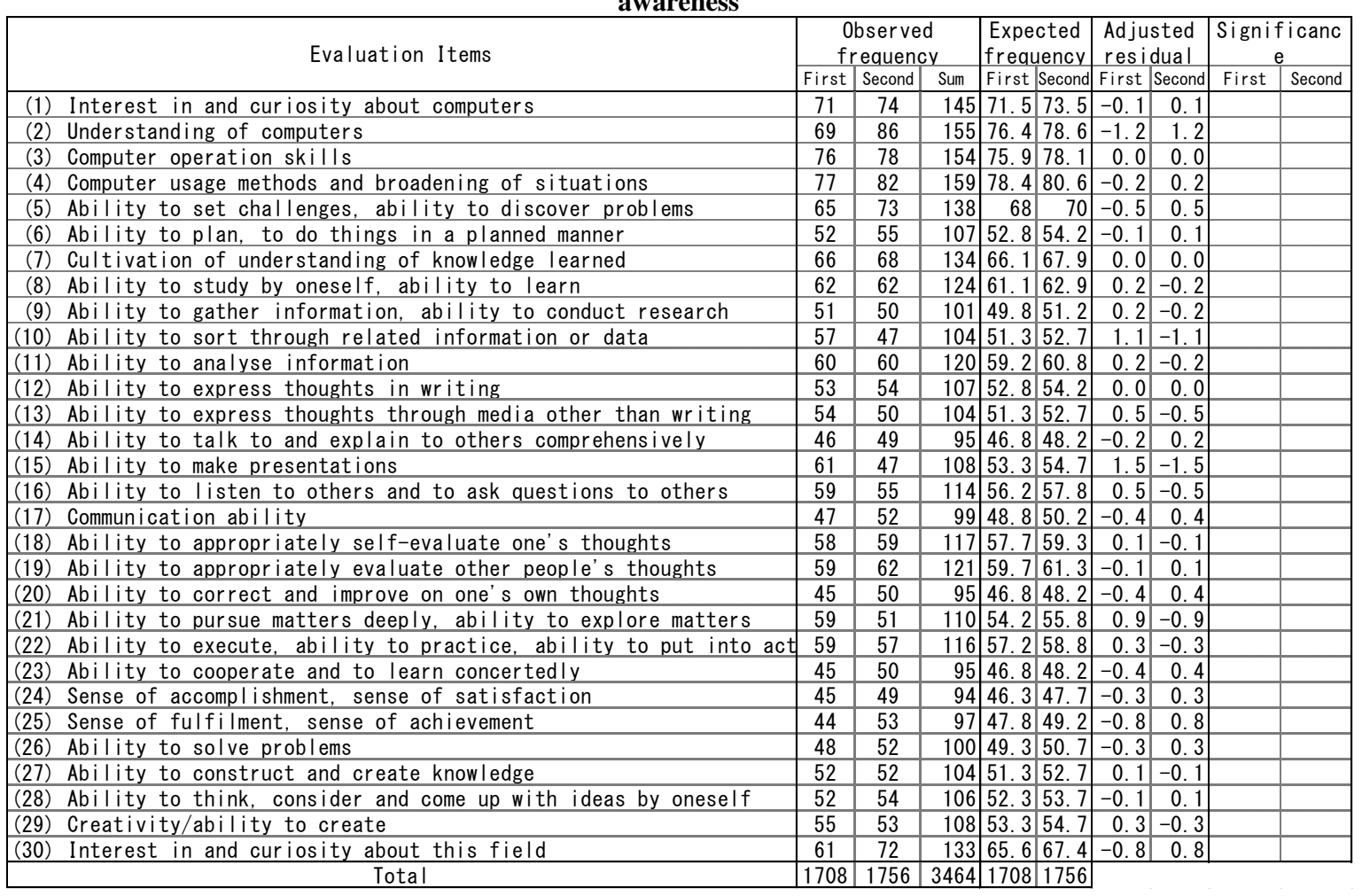

Table 6. Results of $\chi^{2}$ test by using frequency distribution of the number of activities enumerated for each activity

\begin{tabular}{|c|c|c|c|c|c|c|c|c|c|}
\hline \multirow[t]{2}{*}{ Activities } & \multicolumn{3}{|c|}{$\begin{array}{c}\text { Observed } \\
\text { frequency }\end{array}$} & \multicolumn{2}{|c|}{\begin{tabular}{|l} 
Expected \\
frequency
\end{tabular}} & \multicolumn{2}{|c|}{$\begin{array}{l}\text { Adjusted } \\
\text { residual }\end{array}$} & \multicolumn{2}{|c|}{$\begin{array}{l}\text { Significance } \\
\text { probability }\end{array}$} \\
\hline & First & Second & Sum & First & Second & First & Second & First & Second \\
\hline 1 to listen to the instruction of the content of an experiment & 70 & 83 & 153 & 75.4 & 77.6 & -0.9 & 0.9 & & \\
\hline 2 to understand the overview of the experiment & 74 & 81 & 155 & 76.4 & 78.6 & -0.4 & 0.4 & & \\
\hline 3 to listen to friends about the content of experiment & 74 & 60 & 134 & 66.1 & 67.9 & 1.4 & -1.4 & & \\
\hline 4 to listen to teachers and TAs about the content of experiment & 31 & 17 & 48 & 23.7 & 24.3 & 2.1 & -2.1 & $*$ & \\
\hline 5 to use a computer & 108 & 142 & 250 & 123 & 127 & -2.0 & 2.0 & & * \\
\hline 6 to use Word & 97 & 98 & 195 & 96.1 & 98.9 & 0.1 & -0.1 & & \\
\hline 7 to use Excel & 92 & 100 & 192 & 94.7 & 97.3 & -0.4 & 0.4 & & \\
\hline 8 to use PowerPoint & 163 & 137 & 300 & 148 & 152 & 1.8 & -1.8 & + & \\
\hline 9 to draw figures with paint & 14 & 20 & 34 & 16.8 & 17.2 & -1.0 & 1.0 & & \\
\hline 10 to decide the title of introduction content & 41 & 29 & 70 & 34.5 & 35.5 & 1.6 & -1.6 & & \\
\hline 11 to research the content of introduction & 70 & 76 & 146 & 72 & 74 & -0.3 & 0.3 & & \\
\hline 12 to organize what to research & 83 & 81 & 164 & 80.9 & 83.1 & 0.3 & -0.3 & & \\
\hline 13 to create explanation to introduce & 70 & 58 & 128 & 63.1 & 64.9 & 1.2 & -1.2 & & \\
\hline 14 to create introduction slides & 144 & 178 & 322 & 159 & 163 & -1.7 & 1.7 & & + \\
\hline 15 to add animation in the slides & 36 & 47 & 83 & 40.9 & 42.1 & -1.1 & 1.1 & & \\
\hline 16 to record narrations to introduce & 58 & 54 & 112 & 55.2 & 56.8 & 0.5 & -0.5 & & \\
\hline 17 to explain the content of the introduction slides to friends & 45 & 20 & 65 & 32 & 33 & 3.2 & -3.2 & $* * *$ & \\
\hline 18 to ask questions about the introduction slides to friends & 32 & 31 & 63 & 31.1 & 31.9 & 0.2 & -0.2 & & \\
\hline 19 to evaluate own introduction slides & 42 & 31 & 73 & 36 & 37 & 1.4 & -1.4 & & \\
\hline 20 to reevaluate own introduction slides & 27 & 22 & 49 & 24.2 & 24.8 & 0.8 & -0.8 & & \\
\hline 21 to reevaluate own introduction slides again & 28 & 20 & 48 & 23.7 & 24.3 & 1.3 & -1.3 & & \\
\hline 22 to watch others' introduction slides & 34 & 32 & 66 & 32.5 & 33.5 & 0.4 & -0.4 & & \\
\hline 23 to watch others introduction slides again & 25 & 25 & 50 & 24.7 & 25.3 & 0.1 & -0.1 & & \\
\hline 24 to evaluate others' introduction slides & 20 & 33 & 53 & 26.1 & 26.9 & -1.7 & 1.7 & & \\
\hline 25 to reevaluate others' introduction slides & 24 & 32 & 56 & 27.6 & 28.4 & -1.0 & 1.0 & & \\
\hline 26 to analyze evaluation from others about the introduction slides & 23 & 30 & 53 & 26.1 & 26.9 & -0.9 & 0.9 & & \\
\hline 27 to analyze the comments from others about the introduction slides after revision & 10 & 19 & 29 & 14.3 & 14.7 & -1.6 & 1.6 & & \\
\hline 28 to compare self evaluation with other's evaluation & 19 & 32 & 51 & 25.1 & 25.9 & -1.7 & 1.7 & & + \\
\hline 29 to revise the introduction slides & 29 & 32 & 61 & 30.1 & 30.9 & -0.3 & 0.3 & & \\
\hline 30 to write a report & 59 & 63 & 122 & 60.2 & 61.8 & -0.2 & 0.2 & & \\
\hline 31 to revise the final report & 26 & 22 & 48 & 23.7 & 24.3 & 0.7 & -0.7 & & \\
\hline 32 to revise the report according to the teacher's feedback after submission & 25 & 26 & 51 & 25.1 & 25.9 & 0.0 & 0.0 & & \\
\hline 33 others & 15 & 25 & 40 & 19.7 & 20.3 & -1.5 & 1.5 & & \\
\hline Total & 1708 & 1756 & 3464 & 1708 & 1756 & & & & \\
\hline
\end{tabular}


17 were significantly many in commodity slides. In creating the product introduction slide, it is more useful "4. to ask a teacher or TA experiment content" and "17. to explain a product recommendation slide to a friend" than in creating the slide of book introduction. It has a tendency toward being more useful "8. to use PowerPoint" than in creating the slide of book introduction. This means that in creating the product introduction slide it is useful to ask a teacher experiment content, to explain a slide creating to a friend and to use PowerPoint in comparison with creating the book introduction slide. These skills are earned around the beginning by acquiring experience.

In the other hand, the number of activity " 5 . to use a computer" was significantly many in creating book introduction slides. The numbers of activities " 14 . to create introduction slides" and "28. to compare selfevaluation with other's evaluation" had a tendency toward being significantly many in creating book introduction slides. This means that in the book introduction slide, it is more useful to use a computer, to create slides, and to compare self-evaluation with other's evaluation than in creating the production introduction slide because creating introduction slide is second. These skills are gradually acquired by repeating activities relating to them.

\subsection{About change in evaluation by others through two viewings}

It was recognized that all of the following four items related to the narration improved: (14) Is it easy to hear the voice?; (15) Are sound and BGM appropriate?; (16) Is the time distribution appropriate?; (17) Is the narration devised to understand explanation?

The mean rating scale value of the whole four items slightly rises to 3.4 from 3.2. It is thought that the first average rating scale value was low because there were many students who first record narration and many students recorded it in small voice such that their voice hears to the next student or not. It is estimated that average rating scale value became higher because almost students improved the second time so as to hear.

It was recognized that all of the following five items related to the explanation improved: (1) Is the composition of the whole explanation appropriate?; (2) Does the explanation accord with a title?; (3) Are you interested in explanation?; (4) Is there a contrivance of clarity in explanation?; (5) Can you understand the book which you were introduced? The mean rating scale value of the whole five items slightly rises to 3.4 from 3.2 .

As students corrected explanation to become interested in clearly along peer evaluations pointed out, it is estimated that explanation changed so that other students think that they want to read the book introduced. It was recognized that all of the following eight items related to the slide improved: (6) Does each slide accord with explanation?; (7) Is a slide devised to understand explanation?; (8) Is the composition of the whole slide appropriate?; (9) Is the background of the slide appropriate?; (10) Are the size and the color of the letter appropriate?; (11) Is the thing using for explanation appropriate?; (12) Is the object performing animation appropriate?; (13) Is the target movement performing animation smooth? The mean rating scale value of the whole eight items slightly rises to 3.4 from 3.2.

As students corrected slides to put animation, to make character large, and to devise slides along peer evaluations pointed out, it is estimated that slides were changed so that it is easy to review slides introduced.

\subsection{About relationship between self- evaluation and evaluation by others}

For responses to self-evaluation of 18 items according to 26 students $(\mathrm{N}=468)$, correlation coefficient between the self-evaluations in the first and second times is $0.43 * *$. This means that a significant correlation is recognized between these evaluations with medium degree.

The correlation coefficient $r$ between the evaluations by others in the first and second times is $\mathrm{r}=0.75^{* *}$. This means that a significant correlation is recognized between these evaluations with strong degree.

In addition, the correlation coefficient $r$ between the self-evaluation and evaluation by the others in the first time are $\mathrm{r}=0.30 * *$. This means that a significant correlation is recognized between these two evaluations with weak degree.

The correlation coefficient $r$ between the selfevaluation and evaluation by the others in the second time are $\mathrm{r}=0.25^{* *}$. This means that a significant correlation is recognized between these two evaluations with weak degree.

These revealed that two times of rating scale value in evaluation by others resembles than selfevaluation. These show that the similarity between the self-evaluation and evaluation by others are smaller than similarity of each evaluation.

\subsection{About comments in evaluation by others}

Text mining was conducted for the free description in the evaluation by others in creating the book introduction slide and a noun phrase of the frequency up to the 50th place was extracted. Frequency of 50 noun phrases in the first and the second times is 520 and 543 respectively. In this situation I conducted cluster analysis by the Ward method and classified phrases because there was little frequency and chi square test was not possible. As a result, 50 noun 
phrases could be classified into three clusters. The frequency was added up for each of the three clusters. For a cross-tabulation table of the three clusters in 2 times, chi square test was conducted.

As a result, the deflection of the frequency was not significant $\left(\chi^{2}(2)=0.7, p>.05\right)$. This means that the contents of the free description are not different greatly for two times in creating the book introduction slide.

Text mining also was conducted for the free description in the evaluation by others in creating the product introduction slide and a noun phrase of the frequency up to the 50th place was extracted. Frequency of 50 noun phrases in the first and the second times is 627 and 556 respectively. Cluster analysis was conducted by the Ward method and classified 50 phrases. As a result, 50 noun phrases could be classified into three clusters. The frequency was added up for each of the three clusters. For a cross-tabulation table of the three clusters in 2 times, chi square test was conducted. As a result, the deflection of the frequency was significant $\left(\chi^{2}(2)=\right.$ 9.1, p<.05).

As the result of residual analysis, the first frequency of the third cluster which consists of two phrases, "voice and character", was 234 and significantly more than expected frequency. The second frequency was 162 and less than it. The first frequency of the first cluster which consists of 44 phrases, "image, figure, explanation, product, etc.", was 281 and tended to be significantly less than expected frequency. The second frequency was 276 and tended to be more than it. The first frequency of the second cluster which consists of 4 phrases, "narration, scene, slide, and interesting", was 112. The second frequency was 118. Deflection in the second cluster was not recognized.

This means that in creating the product introduction slide the free description included much for voice in the narration and slide contents in the first time, and changed to point a little them in the second time. In addition, the free description included a little for image, figure, explanation, etc. in the first time. Because their phrases are used more appropriately and the explanation improved in the second time, indication to praise for other works increased.

\subsection{About Correlation between reports and awareness}

The items where significant correlation was provided mean that the greater the elongation of ability to gather information and ability to sort through related information is, the more the student submits report. The student who has much presentation number of times of the report is the person who submits the report with the error or insufficient report many times. It is thought that a student might feel that ability to gather information and ability to sort through related information improve when I finally received a report. Such a student generally has relatively low ability to write in the first time. In addition, this means that the less the presentation number of times of the report is, the higher the score of the report is. Because the student with less presentation number of times of the report writes the report with few errors in the beginning and submits the report after appropriately correcting the matter which I pointed out, their reports acquire a high score. This is the result that I almost feel it every day.

\section{Conclusion}

In this study, we designed and practiced a course to make students create PowerPoint slides for book recommendation by applying the idea of active learning. Students selected books they recommended, researched them, considered the contents of the slides, created the slides, added animations and recorded narrations. Furthermore, they watched others' slides and learned from them. They mutually evaluated and commented. After all this, they revised, watched and evaluated the slides again. By interacting with other students for completing the task in this way, they were able to experience active evaluation and revision activities. In consequence, they enhanced problem-solving skills and nurtured active thinking through the classroom practice.

The findings from this class can be summarized as follows.

(1) Activities concerning asking a question or narrations are useful in enhancing awareness relating to listening and evaluation.

(2) Activities relating to slide creation are useful in enhancing awareness concerning task setting, deep understanding and interest.

(3) Activities relating to software use are useful in enhancing awareness relating to computers.

(4) Activities useful for improving attitude are the same in creating product and book introduction slide.

(5) Self-evaluation improved overall. All of items in self-evaluation improved.

(6) Evaluation by others improved overall. All of items in evaluation by others improved.

(7) Two times of rating scale value in evaluation by others resembles than self-evaluation.

In the future, we would like to compare the effects of the above-mentioned storytelling [9], [10] with the effects of this class. We would also like to apply innovation to class methods to improve learning ability for students with a wide range of learning abilities. 


\section{Acknowledgements}

This work was supported by JSPS KAKENHI Grant Number JP25350364. The author would like to express appreciation to the students who were surveyed and who helped collect educational information.

\section{References}

[1] Ballast, K.H., et al., "The effect of digital storytelling on sixth grade students' writing and their attitudes about writing", Proceedings of Society for Information Technology \& Teacher Education International Conference 2008, pp.875-879, USA (2008).

[2] Barrett, H.C., "Researching and evaluating digital storytelling as a deep learning tool", Proceedings of Society for Information Technology \& Teacher Education International Conference, pp.647-652, USA (2006).

[3] Figg, C., McCartney, R., and Gonsoulin W., "Impacting academic achievement with student learners teaching digital storytelling to others: The ATTTCSE digital video project", Contemporary Issues in Technology and Teacher Education (CITE Journal), 10(1), pp.38-79 (2010).

[4] Kelleher, C. and Pausch, R., "Using storytelling to motivating programming", Communications of the ACM, 50(7), 59 - 64 (2007).

[5] Ku, Y., Chen Y., and Chang, W., "Development of early literacy skills: The nature and relationship between oral and written language comprehension", Proceedings of the 10th Hawaii International Conference on Education, pp.1-7, Hawaii, USA (2012).

[6] Ministry of Education, Culture, Sports, Science and Technology Council, "Continue learn towards the qualitative transformation of university education in order to build a new future - to the university to continue learning throughout the life and foster the ability to think proactively (Report)", http://www.mext.go.jp/b_menu/ shingi/chukyo/chukyo0/toushin/1325047.htm (2012). (Access Date: 3nd February, 2017)

[7] Miyaji, I., "A trial of information literacy education to foster the problem-solving ability by introducing estimating activities into the class", Transaction of Japanese Society for Information and Systems in Education, 23(4), pp.176-184 (2006).

[8] Miyaji, I. (Ed.), Toward Blended Learning from Elearning, Kyoritu-Shuppan, Tokyo (2009).

[9] Miyaji, I., "The Effects of digital storytelling through the strategy of phased evaluation and correction", ITHET2010--9th International Conference on Information Technology Based Higher Education and Training, pp.129135, Cappadocia, Turkey (2010).

[10] Miyaji, I., "Effects of creating three kinds of digital storytelling on student attitude", Journal of Modern Education Review, 2(5), pp.243-262 (2012).
[11] Miyaji, I., "Change of attitude in class for creating slides to present product", Proceedings of the 2nd International Conference on e-Learning, e-Education, Online Training, eLEOT2015, pp.25-30, Novedrate, Italy (2015).

[12] Miyaji, I., Useful Activities for Improving Awareness and Change of Evaluation by Others in Class for Creating Slides to Present Product, International Journal for Cross-Disciplinary Subjects in Education (IJCDSE), Special Issue Vol.5, Issue 4, pp.2661-2671 (2015)

[13] Miyaji, I., "Improvement in computer literacy through creating digital storytelling", American Journal of Education Research, 4(1), pp.54-63 (2016).

[14] Miyaji, I., "Awareness raising in creating book recommendation slides by means of PowerPoint", Proceedings of the International Conference on Education and New Developments, pp.202-206, Liblijna, Slovenia (2016).

[15] Miyaji, I., "Classification and characteristics of student groups using change of attitude in class for creating slides to present product," Asian Education Studies, 1(2), pp.56-68 (2016).

[16] Robin, B. R., "Digital storytelling: A powerful technology tool for the 21 st century classroom", Theory into Practice, 4(3), pp.220-228 (2008).

[17] Tsou, W., Wang, W., and Tzeng, Y., “Applying a multimedia storytelling website in foreign language learning", Computers \& Education, 47(1), pp.17-28 (2006).

[18] Zipes, J., Creative Storytelling: Building Community, Changing Lives, Routledge, New York \& London (1995). 